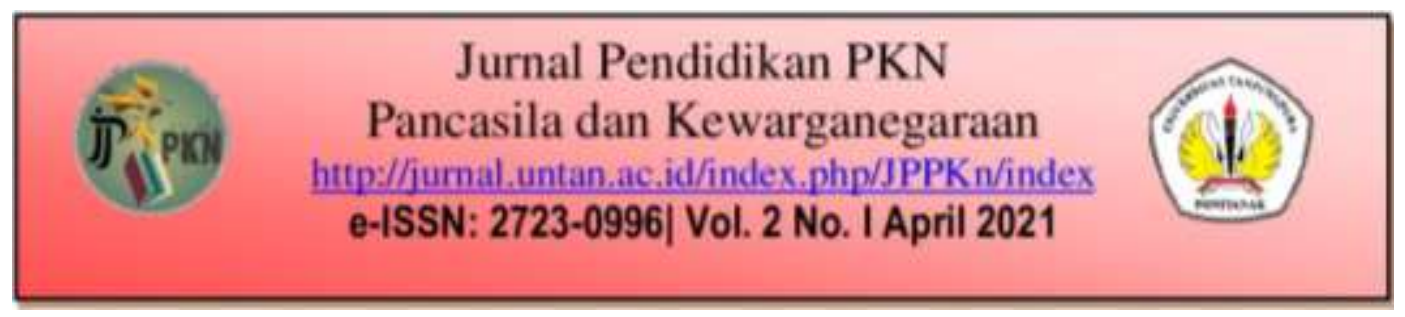

\title{
ANALISIS PENGARUH PENERIMAAN PESERTA DIDIK BARU MELALUI SISTEM ZONASI TERHADAP PRESTASI BELAJAR
}

\author{
Sulaiman $^{{ }^{*}}$, Laila Nurfitrah Lubis ${ }^{1}$, Rizky Aditya ${ }^{1}$ \\ ${ }^{1}$ Politeknik Negeri Pontianak, Pontianak, Indonesia \\ *imansulaiman137@yahoo.co.id
}

\begin{abstract}
ABSTRAK
Penelitian ini bertujuan untuk mengetahui pengaruh sistem zonasi terhadap prestasi belajar siswa kelas XI SMA Negeri 6 Pontianak. Dalam penelitian ini diambil sampel sebanyak 88 orang dengan menggunakan analisis regresi. Sumber data yang diperoleh adalah data primer dan data sekunder. Dengan pendekatan kuantitatif. Teknik pengumpulan data melalui teknik wawancara, observasi dan dokumentasi. Teknik analisis data menggunakan uji asumsi, analisis deskriptif dan analisis statistik dengan regresi linier menggunakan SPSS (Social Sciences Program Statistics) versi 22.0. Hasil penelitian menunjukkan bahwa sistem zonasi terhadap prestasi belajar siswa kelas XI SMA Negeri 6 Pontianak berpengaruh positif. Berdasarkan hasil perhitungan diperoleh nilai thitung $(6,863)>$ t tabel $(0,270)$ dan nilai signifikan $(0,000)<0,05$, maka hipotesis (H1) diterima, artinya terdapat pengaruh positif yang signifikan antara variabel sistem zonasi terhadap Prestasi Belajar Siswa Kelas XI SMA Negeri 6 Pontianak.
\end{abstract}

Kata Kunci: Sistem Zonasi, Prestasi, Pembelajaran

\section{ABSTRACT}

This study aims to determine the effect of the zoning system on learning achievement in class XI SMA Negeri 6 Pontianak. In this study, a sample of 88 people was taken using regression analysis. The data sources obtained are primary data and secondary data. With a quantitative approach. Data collection techniques through interview techniques, observation and documentation. Data analysis techniques used assumption tests, descriptive analysis and statistical analysis with linear regression using SPSS (Social Sciences Program Statistics) version 22.0. The results showed that the zoning system on student achievement in class XI SMA Negeri 6 Pontianak had a positive effect. Based on the results of the calculation, the value of tcount (6.863)> $t$ table (0.270) and a significant value $(0.000)<0.05$, then the hypothesis (H1) is accepted, meaning that there is a significant positive effect between the zoning system variable on Student Achievement in Class XI SMA Negeri 6 Pontianak.

Keywords: Zoning System, Achievement, Learning 


\section{PENDAHULUAN}

Dunia pendidikan yang semakin maju tidak bisa dilepaskan dari peran masyarakat. Pendidikan adalah hal yang penting dan tidak dapat dipisahkan dari kehidupan (Dewantara et al., 2020). Setiap bangsa dan generasi memiliki dasar dan tujuan pendidikan tertentu. Tentunya dasar dan tujuan itu disesuaikan dengan citacita, keinginan dan kebutuhan. Salah satu upaya nyata pemerintah dalam rangka pemerataan pendidikan ini pemerintah mengeluarkan aturan baru dalam penerimaan peserta didik melalui Peraturan menteri pendidikan dan kebudayaan no 17 tahun 2017 tentang Penerimaan Peserta Didik Baru (PPDB), yang di Dalam permendikbud tersebut, diatur mengenai sistem zonasi yang harus diterapkan sekolah dalam menerima calon peserta didik baru (Slameto, 2010). Sistem Zonasi adalah sebuah sistem pengaturan proses penerimaan siswa baru sesuai dengan wilayah tempat tinggal. Berdasarkan Permendikbud Nomor 17 Tahun 2017, dengan menerapkan sistem zonasi, sekolah yang diselenggarakan oleh pemerintah daerah wajib menerima calon peserta didik yang berdomisili pada radius zona terdekat dari sekolah. Domisili calon peserta didik tersebut berdasarkan alamat pada kartu keluarga yang diterbitkan paling lambat enam bulan sebelum pelaksanaan PPDB (Slamet Santoso, 2010). Dalam pelaksanaan di lapangan, penerapan sistem zonasi ini mendapati berbagai persoalan diantaranya yaitu adanya kondisi peserta didik yang diterima melalui sistem zonasi memiliki kemampuan pemahaman materi dan motivasi belajar yang cukup rendah Selama ini SMAN 6 Pontianak dikenal sebagai salah satu sekolah favorit yang menerima siswa baru berdasarkan nilai hasil ujian sekolah, prestasi akademik dan non akademik, serta tes tertulis.

Berdasarkan data yang diperoleh menyebutkan terdapat 293 siswa yang diterima melalui sistem zonasi dari total 399 siswa yang diterima pada penerimaan peserta didik baru tahun pelajaran 2020/2021. Menurut salah satu guru SMAN 6 Pontianak adanya sistem zonasi menyebabkan pemahaman materi peserta didik relatif cukup rendah, dikarenakan tidak meratanya kemampuan pemahaman materi peserta didik yang diterima melalui sistem zonasi berbeda dengan peserta didik yang masuk melalui sistem prestasi karena peserta didik tersebut benar-benar ditest untuk dapat diterima di SMAN 6 Pontianak. Selain itu tingkat motivasi peserta didik dalam belajar tergolong cukup rendah, hal ini dikarenakan peserta didik malas untuk belajar dan lebih mengandalkan temannya yang masuk dalam jalur prestasi karena dianggap memiliki kemampuan pemahaman belajar yang lebih tinggi dari mereka (Wijaya et al., 2020). Dalam 
pembelajaran para peserta didik yang diterima melalui sistem zonasi kebanyakan kurang memperhatikan penjelasan atau materi yang diberikan oleh guru, karena mereka sibuk dengan kegiatan yang lain seperti mengobrol atau bermain $\mathrm{HP}$, hal ini disebabkan peserta didik pasif baik bertanya maupun mencari di buku pedoman terkait materi yang kurang dimengerti pada saat proses belajar mengajar. Prestasi belajar yang dimiliki para peserta didik yang diterima melalui sistem zonasi pun tergolong rendah, terlihat dari data nilai hasil ujian tengah semester mata pelajaran Ekonomi, dari 293 peserta didik, peserta didik diantaranya mendapatkan nilai yang belum memenuhi kriteria kelulusan minimal yaitu 69 (Hasibua, 2010).

Zonasi sendiri berasal dari kata zona yaitu kawasan atau area yang memiliki fungsi dan karakteristik lingkungan yang spesifik, (Hamalik, 2010) dalam bahasa inggris adalah Zoning. Pada beberapa negara peraturan zonasi (zoning regulation) dikenal juga dengan istilah land development code, zoning code, zoning ordinance, zoning resolution, zoning bylow, urban code, panning act, dan lain-lain. Zonasi sendiri menurut Babcock yang dikutip oleh Korlena dkk didefinisikan sebagai: "Zoning is the division of a municipality into distrcts for the purpose of reguating the use of private land" (A.M Sardiman, 2012). Pembagian wilayah menjadi beberapa kawasan dengan aturan-aturan hukum yang ditetapkan lewat peraturan zonasi, pada prinsipnya bertujuan memisahkan pembangunan kawasan industri dan komersial dari kawasan perumahan. Menurut Barnet peraturan zonasi ini lebih dikenal dengan istilah populer zoning regulation, dimana kata zoning yang dimaksud merujuk pada pembangian lingkungan kota ke dalam zona-zona pemanfaatan ruang dimana di dalam tiap zona tersebut ditetapkan pengendalian pemanfaatan ruang atau diberlakukan ketentuan hukum yang berbedabeda. Sedangkan menurut KBBI adalah pembagian atau pemecahan suatu areal menjadi beberapa bagian, sesuai dengan fungsi dan tujuan pengelolaan (Ahmad Djunaedi, 2011).

Dari pengertian menurut ahli dapat peneliti simpulkan bahwa sistem zonasi adalah pembagian wilayah kedalam beberapa zona. sedangkan dalam pendidikan khususnya pada penerimaan peserta didik baru tahun 2017/2018 sistem zonasi yaitu suatu sistem pembagian zona sekolah yang mengedepankan jarak antara sekolah dengan rumah. Sistem zonasi ini sekolah wajib menerima calon peserta didik yang berdomisili pada radius zona terdekat dari sekolah paling sedikit $90 \%$ dari total jumlah keseluruhan peserta didik yang diterima (Djamarah, 2011). 
Dalam penelitian ini peneliti ingin mengetahui apakah ada Pengaruh penerimaan peserta didik baru melalui sistem donasi terhadap prestasi belajar siswa pada siswa kelas XI SMA Negeri 6 Pontianak. Siswa yang dijadikan responden secara keseluruhan berjumlah 88 orang dengan kriteria nilai tertinggi di tiap kelas masing-masing.

\section{METODE PENELITIAN}

\section{Pendekatan Penelitian}

Dalam penelitian ini menggunakan pendekatan penelitian kuantitatif yaitu peneliti mengumpulkan data dengan menetapkan terlebih dahulu konsep sebagai sebuah variabel yang berhubungan yang berasal dari teori yang sudah ada yang diperoleh oleh peneliti dan kemudian mencari datanya dengan menggunakan kuesioner untuk pengukuran sebuah variable (Arikunto, 2002).

\section{Jenis Penelitian}

Berdasarkan tujuan penelitian yang ditetapkan, maka penelitian ini adalah penelitian eksplanatori (Explanatory Research) yaitu penelitian yang menyoroti hubungan antara variabel-variabel penelitian dan menguji hipotesis yang telah dirumuskan (Singarimbun \& Efendi, 1995).

\section{Populasi}

Populasi adalah Keseluruhan nilai atau sumber data yang mungkin diperoleh melalui hasil perhitungan atau pengukuran, baik yang bersifat kuantitatif maupun yang bersifat kualitatif dari karakteristik tertentu mengenai sekumpulan objek yang lengkap dan jelas yang ingin dipelajari dan dianalisa sifat-sifatnya (Arikunto, 2006). Dalam penelitian ini yang menjadi populasi adalah seluruh siswa kelas XI SMAN 6 Pontianak tahun pelajaran 2020/2021.

\section{Sampel}

Sedangkan sampel adalah sebagian dari jumlah dan karakteristik yang dimiliki oleh populasi tersebut (Husein \& Riduwan, 2004). Dalam penelitian ini yang menjadi sampel adalah 88 orang mahasiswa yang memiliki nilai Tinggi, diambil representatif maka dihitung dengan menggunakan rumus Slovin dalam (Prasetiyo et al., 2020) dengan presisi $10 \%$, rumusnya sebagai berikut: 


$$
n=\frac{N}{1+N(e)^{2}}
$$

Dimana:

$\mathrm{n}=$ jumlah sampel

$\mathrm{N}=$ jumlah populasi

$\mathrm{e}=$ persen kelonggaran ketidaktelitian karena kesalahan pengambilan sample yang masih dapat ditolerir atau diinginkan.

Berdasarkan rumus tersebut, maka jumlah sampel yang diperoleh adalah:

$$
\begin{gathered}
\mathrm{n}=\frac{750}{1+(100)(0,1)^{2}} \\
=88
\end{gathered}
$$

\section{Sumber Data}

Jenis data penelitian ada dua, yakni : data primer dan data sekunder. Karena yang diteliti adalah perilaku responden maka data utama yang diperlukan adalah untuk mendukung hipotesis penelitian ini adalah data primer.(Husein \& Riduwan, 2004). Data primer adalah data orang pertama yakni data yang berasal langsung dari sumber data yang dikumpulkan secara khusus dan berkaitan langsung dengan permasalahan yang diteliti. Sumber data primer pada penelitian adalah para siswa kelas XI SMAN 6 Pontianak tahun pelajaran 2020/2021.

Selain data primer, digunakan juga data sekunder untuk mendukung penelitian ini. Sumber data sekunder yang dimaksud adalah buku-buku, jurnal ilmiah, majalah, literatur dan internet yang berkaitan dengan objek penelitian.(Supardi, 2005).

\section{Teknik Pengumpulan Data}

Pengumpulan data dalam penelitian ini dilakukan melalui teknik wawancara, kuesioner, dan studi dokumentasi.

a) Wawancara digunakan untuk mengetahui kondisi dan fakta yang terjadi di lokasi penelitian. Data sekunder ini di dapat dari beberapa pihak dalam organisasi.

b) Kuesioner adalah daftar pertanyaan yang diajukan kepada responden untuk memperoleh data yang berkaitan dengan penelitian. Kuesioner ini dimaksudkan untuk memperoleh data deskriptif dalam menguji hipotesis. Pengumpulan data dilakukan dengan cara membagikan kusioner tersebut kepada para mahasiswa jurusan administrasi bisnis 
Responden kemudian diminta mengisi kuesioner sesuai dengan petunjuk yang telah tersedia.

c) Studi Dokumentasi. Penelaahan data dengan jalan mengumpulkan informasi-informasi melalui, dokumen-dokumen atau arsip-arsip yang berupa laporan-laporan maupun catatan yang tersedia di organisasi dan sesuai dengan permasalahan.

Data yang sudah terkumpul dari responden diolah dengan skala Likert (Supardi, 2005). Skala Likert umumnya digunakan untuk menilai pendapat atau persepsi dari responden tentang perilaku dan fenomena sosial yang dipakai oleh peneliti dalam variabel penelitian. Analisa diawali dengan data responden dan kemudian diukur tingkat kepentingan responden terhadap indikator-indikator yang diajukan dalam kuesioner dengan menggunakan skala 5 tingkat (Riduwan, 2006b). Menggunakan skala Likert yaitu untuk mengukur sikap dan persepsi seseorang atau kelompok tentang kejadian atau gejala sosial. Dalam penelitian ini, penulis tidak menggunakan item ragu-ragu atau netral karena di khawatirkan jawaban responden akan mengarah ke jawaban tersebut, yang dapat membuat penelitian ini menjadi bias. Oleh karena itu (1) Sangat Tidak Setuju, (2) Tidak Setuju, (3) Kurang Setuju, (4) Setuju, dan (5) Sangat Setuju (Riduwan, 2006b).

\section{Uji Validitas}

Uji validitas digunakan untuk menguji instrument agar memberikan hasil sesuai dengan tujuan. Menurut (Supardi, 2005), validitas menunjukkan tingkat instrument penelitian penelitian mengukur apa yang diinginkan dan dapat mengungkapkan data dan variabel yang diteliti secara tepat. Pengujian validitas dilakukan dengan analisa butir. Sebuah instrumen dikatakan valid, jika koefisien korelasinya $\geq 0,3$ dengan $\alpha 0,05$. (Robbins, 2002). Untuk menguji validitas responden digunakan rumus korelasi "product moment", dengan rumus sebagai berikut:

$r_{x y}=\frac{n \sum x y-\sum x \sum y}{\left.\sqrt{\left(n \sum x^{2}\right.}-\left(\sum x\right)^{2}\right)\left(n\left(\sum y^{2}\right)-\left(\sum y\right)^{2}\right)}$

Dimana:

$\mathrm{r}=$ koefisien korelasi

$\mathrm{x}=$ skor jawaban tiap item

$\mathrm{y}=$ skor total

$\mathrm{n}=$ jumlah responden 
Jika $t$ hitung $>t$ tabel, berarti valid

Jika $t$ hitung $<\mathrm{t}$ tabel, berarti tidak valid

\section{Uji Reliabilitas}

Menurut (Supardi, 2005) Reliabilitas mengarah pada keajegan suatu alat ukur, di mana tingkat reliabilitas memperhatikan sejauh mana alat ukur dapat diandalkan dan dipercaya. Bila suatu alat pengukur dipakai dua kali untuk mengukur gejala yang sama dan hasil pengukuran yang diperoleh relatif konsisten, maka alat pengukur tersebut reliabel. Dengan kata lain, reliabilitas menunjukkan konsistensi suatu alat pengukur di dalam mengukur alat yang sama.

Menurut (Arikunto, 2002: 160) instrumen dikatakan andal (reliabel) apabila memiliki keandalan sebesar 0,60 atau lebih. Uji reliabilitas ini dilakukan dengan menggunakan teknik alpha cronbach $(\alpha)$, dengan rumus sebagai berikut :

$r_{11}=\left[\frac{k}{k-1}\right]\left[1-\frac{\sum a^{2} b}{a^{2} 1}\right]$

Dimana :

$\mathrm{r}_{11}=$ reliabilitas instrumen

$\mathrm{k} \quad=$ banyaknya butir pertanyaan

$\sum \alpha^{2} \mathrm{~b}=$ jumlah varians butir

$\alpha^{2} 1=$ varians total

Kriteria indeks reliabilitas menurut (Arikunto, 2002) sebagai berikut :

Tabel.1 Kriteria Indeks Reliabilitas

\begin{tabular}{|l|l|l|}
\hline No. & Interval & Kriteria \\
\hline 1. & $<0,200$ & Sangat rendah \\
2. & $0,200-0,399$ & Rendah \\
3. & $0,400-0,599$ & Cukup \\
4. & $0,600-0,779$ & Tinggi \\
5. & $0,800-1,00$ & Sangat Tinggi \\
\hline
\end{tabular}

Sumber : Arikunto, 2002 


\section{HASIL DAN PEMBAHASAN}

\section{Uji Validitas}

Uji validitas adalah tingkat keandalan alat ukur yang digunakan. Uji validitas digunakan untuk mengetahui kelayakan butir-butir dalam suatu daftar pertanyaan atau pernyataan dalam mendefinisikan variabel.(Riduwan, 2006a). Kriteria penilaian uji validitas adalah:

1. Apabila $\mathrm{r}$ hitung $>\mathrm{r}$ tabel, maka item kuesioner tersebut valid.

2. Apabila $\mathrm{r}$ hitung $<\mathrm{r}$ tabel, maka dapat dikatakan item kuesioner tidak valid.

Tabel 2. Variabel Sistem Zonasi (X)

\begin{tabular}{|c|l|l|l|}
\hline Pernyataan & rhitung & rtabel & Ket \\
\hline 1 & $.576^{* *}$ & .270 & Valid \\
\hline 2 & $.625^{* *}$ & .270 & Valid \\
\hline 3 & $.698^{* *}$ & .270 & Valid \\
\hline 4 & $.678^{* *}$ & .270 & Valid \\
\hline 5 & $.569^{* *}$ & .270 & Valid \\
\hline 6 & $.453^{* *}$ & .270 & Valid \\
\hline 7 & $.660^{* *}$ & .270 & Valid \\
\hline 8 & $.635^{* *}$ & .270 & Valid \\
\hline 9 & $.616^{* *}$ & .270 & Valid \\
\hline 10 & $.600^{* *}$ & .270 & Valid \\
\hline
\end{tabular}

Sumber: Hasil Olahan Data Statistik (2021)

Berdasarkan tabel di atas dapat diketahui bahwa nilai $r$ hitung pada pernyataan 1 sampai 10 dalam kuisioner lebih besar dari $\mathrm{r}$ tabel $(0,270)$. Dengan demikian, dapat disimpulkan bahwa semua pernyataan pada dalam indikator Sistem Zonasi (X) adalah valid dan dapat digunakan (Alam, 2019).

Tabel 3. Variabel Prestasi Belajar (Y)

\begin{tabular}{|c|l|l|l|}
\hline Pernyataan & rhitung & rtabel & Ket \\
\hline 1 & $.466^{* *}$ & .270 & Valid \\
\hline 2 & $.739^{* *}$ & .270 & Valid \\
\hline 3 & $.741^{* *}$ & .270 & Valid \\
\hline 4 & $.648^{* *}$ & .270 & Valid \\
\hline 5 & $.667^{* *}$ & .270 & Valid \\
\hline 6 & $.712^{* *}$ & .270 & Valid \\
\hline 7 & $.593^{* *}$ & .270 & Valid \\
\hline 8 & $.630^{* *}$ & .270 & Valid \\
\hline 9 & $.726^{* *}$ & .270 & Valid \\
\hline 10 & $.583^{* *}$ & .270 & Valid \\
\hline
\end{tabular}

Sumber: Hasil Olahan Data Statistik (2021) 
Berdasarkan tabel di atas dapat diketahui bahwa nilai $r$ hitung pada pernyataan 1 sampai 10 dalam kuisioner lebih besar dari $\mathrm{r}$ tabel $(0,270)$. Dengan demikian, dapat disimpulkan bahwa semua pernyataan pada indikator Prestasi Belajar (Y) adalah valid dan dapat digunakan.

\section{Uji Reliabilitas}

Uji reliabilitas adalah Suatu ukuran yang menunjukkan tingkat kehandalan dalam suatu penelitian. (Singarimbun \& Efendi, 1995). Instrumen penelitian yang reliabel jika suatu instrumen berulang kali digunakan untuk mengukur objek yang sama akan menghasilkan data yang sama. (Singgih Santoso, 2000). Cara mengukurnya adalah dengan menghitung koefisien reliabelitas dan membandingkan dengan cronbanch's alpha yang bernilai 0,6 (lebih besar 0,6 maka reliabel, lebih kecil tidak reliabel). Pada penelitian ini digambarkan dengan cronbach's alpha>cronbach's standard $(0,6)$.

Tabel 4. Uji Reliabilitas

\begin{tabular}{|c|l|l|c|l|}
\hline No & Variabel & $\begin{array}{l}\text { cronbach's } \\
\text { alpha }\end{array}$ & $\begin{array}{l}\text { cronbach's } \\
\text { standard }\end{array}$ & Ket \\
\hline 1 & $\begin{array}{l}\text { Sistem } \\
\text { Zonasi (X) }\end{array}$ & .804 & .60 & Reliabel \\
\hline 2 & $\begin{array}{l}\text { Prestasi } \\
\text { Belajar (Y) }\end{array}$ & .841 & .60 & Reliabel \\
\hline
\end{tabular}

Sumber: Hasil Olahan Data Statistik (2021)

\section{Uji Normalitas}

Pengujian distribusi normal ini digunakan normal probability plot. Sebaran normal merupakan sebuah pendekatan fungsi dari suatu kumpulan yang memiliki ciri khas, seperti pengamatan yang paling banyak dijumpai memiliki nilai di sekitar nilai tengah (mean), pengamatan yang sangat jauh (ke arah kanan dan kiri mean) berjumlah sedikit sekali, memiliki pola yang simetris. Menurut Santoso, (2000; 214) Salah satu cara untuk menguji kenormalan adalah Uji Chi Square, untuk menentukan apakah sebaran data normal atau tidak, dapat dilihat dan nilai probabilitas dibandingkan dengan $\alpha$. Jika nilai probabilitas $<\alpha$ berarti data tersebar normal. Gambar-2 Hasil Uji Normalitas probability plot. 


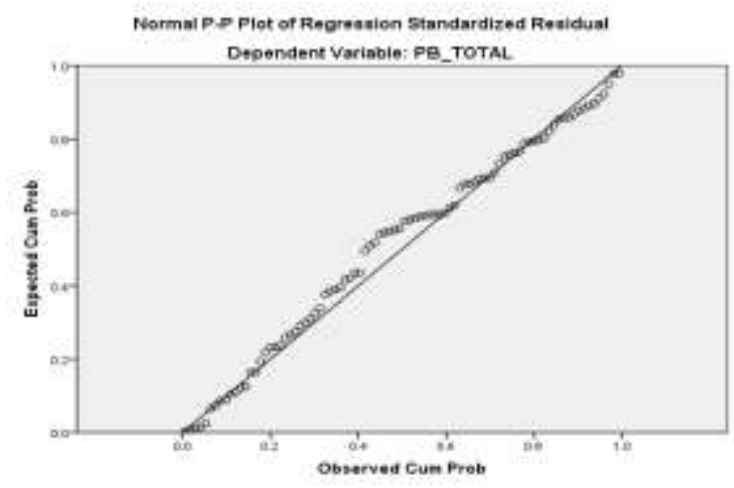

Gambar 1. Uji Normalitas

Pada Gambar 1 grafik normal probability plot terlihat titik-titik menyebar di sekitar garis diagonal, serta penyebarannya mengikuti arah garis diagonal. Sehingga model regresi sesuai dengan asumsi normalitas karena memenuhi kriteria normalitas analisis grafik yang pertama yaitu data berdistribusi normal.

\section{Analisis Regresi Linier Sederhana}

Analisis regresi linier sederhana digunakan untuk mengetahui seberapa besar pengaruh variabel independen sistem zonasi terhadap variabel dependen prestasi belajar. Adapun bentuk persamaan regresi linier sederhana adalah sebagai berikut:

$$
\boldsymbol{Y}=\boldsymbol{a}+\boldsymbol{b} \mathbf{1 X} \mathbf{1}+\boldsymbol{e}
$$

Keterangan:

$\mathrm{Y} \quad=$ prestasi belajar

$a \quad$ intercept (konstanta)

$b 1=$ koefisien regresi untuk $\mathrm{X} 1$

$\mathrm{X} 1=$ komunikasi

$e \quad=\operatorname{error}($ nilai residu)

Berdasarkan pengujian menggunakan software statistic, maka hasil persamaan regresi linier sederhana dapat dilihat sebagai berikut: 
Tabel 5. Uji Regresi Linier Sederhana

\begin{tabular}{|c|c|l|l|c|c|}
\hline & \multicolumn{2}{|l|}{$\begin{array}{l}\text { Unstandardize } \\
\text { d Coefficients }\end{array}$} & $\begin{array}{l}\text { Standardi } \\
\text { zed } \\
\text { Coefficien } \\
\text { ts }\end{array}$ & & \\
\cline { 2 - 6 } & \multicolumn{1}{|l|}{ B } & $\begin{array}{l}\text { Std. } \\
\text { Error }\end{array}$ & Beta & t & Sig. \\
\hline 1 (Constant) & 5.787 & 3.457 & & 1.674 & .098 \\
D_TOTAL & .574 & .084 & .597 & 6.863 & .000 \\
\hline
\end{tabular}

Sumber: Hasil Olahan SPSS

Berdasarkan tabel model-model persamaan regresi yang terbentuk adalah:

$\mathrm{Y}=5,787+0,574 \mathrm{X}+\mathrm{e}$

\section{Pengujian Hipotesis}

\section{Uji Parsial (Uji-t)}

Uji Signifikan Parsial (uji t) digunakan untuk menunjukan seberapa jauh pengaruh antar variabel independen dengan variabel dependen(Martono et al., 2020). Apabila nilai probalitas signifikan lebih kecil dari 0,05 (5\%) maka suatu variabel independen berpengaruh signifikan terhadap variabel dependen. Adapun kriteria adalah:

1. Jika $t$ hitung $>t$ tabel maka Ho ditolak dan Ha diterima.

2. Jika $t$ hitung $<\mathrm{t}$ tabel maka Ho diterima dan Ha ditolak.

Menentukan $\mathrm{t}$ tabel dengan melihat pada $\alpha=5 \%$ yang diperoleh dari degree of freedom dengan rumus: $\mathrm{df}=\mathrm{n}-\mathrm{k}$

Keterangan:

$\mathrm{df}=$ degree of freedom (derajat)

$\mathrm{n}=$ jumlah sampel yang digunakan dalam penelitian yaitu 88

$\mathrm{k}=$ jumlah variabel yang digunakan dalam penelitian yaitu 3 sehingga $\mathrm{t}$ tabel dengan sampel 88, probabilitas 5\% dan df sebesar 93 adalah 1,66298 Berikut adalah tabel uji t dari statistic software: 
Tabel 6. Uji Regresi Linier Sederhana

\begin{tabular}{|c|c|c|c|c|c|}
\hline \multirow{2}{*}{ Model } & \multicolumn{2}{|c|}{$\begin{array}{c}\text { Unstandardized } \\
\text { Coefficients }\end{array}$} & $\begin{array}{c}\text { Standardized } \\
\text { Coefficients }\end{array}$ & & \\
\cline { 2 - 5 } & $\mathrm{B}$ & Std. Error & Beta & $\mathrm{t}$ & Sig. \\
\hline 1 (Constant) & 5.787 & 3.457 & & 1.674 & .098 \\
D_TOTAL & .574 & .084 & .597 & 6.863 & .000 \\
\hline
\end{tabular}

Sumber: Hasil Olahan SPSS

Pengujian hipotesis untuk variabel sistem zonasi dapat dilihat pada tabel uji regresi linear sederhana dengan penjabaran sebagai berikut Variabel sistem zonasi secara parsial berpengaruh secara positif signifikan terhadap prestasi belajar, hal ini dapat dilihat dari nilai thitung (6.863) $>\mathrm{t}$ tabel $(0.270)$ dan nilai signifikan $(0,000)<0,05$, maka hipotesis Ho diterima dan Ha ditolak.

\section{KESIMPULAN}

Dari pembahasan hasil olahan data yang peneliti lakukan dapat dilihat dengan pengujian hipotesis untuk variabel sistem zonasi $(X)$ pada tabel uji regresi linear sederhana dengan penjabaran sebagai berikut Variabel sistem zonasi $(X)$ secara parsial berpengaruh secara positif signifikan terhadap prestasi belajar $(Y)$, yaitu dilihat dari nilai thitung $(6.863)>t$ tabel $(0.270)$ dan nilai signifikan $(0,000)<0,05$, maka hipotesis Ho diterima dan Ha ditolak. Dapat disimpulkan ada pengaruh positif yang signifikan variable system zonasi $(X)$ terhadap prestasi belajar (Y) pada siswa kelas XI SMAN 6 Pontianak tahun pelajaran 2020/2021.

\section{DAFTAR PUSTAKA}

A.M Sardiman. (2012). Interaksi \& Motivasi Belajar Mengajar. Rajawali.

Alam, S. (2019). Pengaruh Komunikasi, Motivasi dan Disiplin Kerja

Terhadap Kinerja Pegawai Lembaga Penjamin Mutu Pendidikan". (Program Studi Magister Managemen Pascasarjana Universitas Tadulako). E-Jurnal Katalogis, 2(1), 135-145.

Arikunto, S. (2002). Metodologi Penelitian Suatu Pendekatan Proposal. PT. Rineka Cipta.

Arikunto, S. (2006). Prosedur Penelitian Suatu Pendekatan Praktis. Rineka 


\section{Cipta.}

Dewantara, J. A., Efriani, E., \& Sulistyarini, S. (2020). Caring National Identity Through Teacher Contributions in the Border: Pancasila Actionistic Basic Implementation. Jurnal Basicedu, 4(3), 649-661. https://doi.org/10.31004/basicedu.v4i3.407

Djamarah, S. B. (2011). Psikologi Belajar. Rineka Cipta.

Hamalik, O. (2010). Proses Belajar Mengajar. PT Bumi Aksara. Huda.

Hasibua, M. S. P. (2010). Manajemen Sumber Daya Manusia. PT Bumi Aksara.

Husein, U., \& Riduwan. (2004). Skala Pengukuran Variabel Penelitian. Alfabeta Persada.

Martono, Dewantara, J. A., \& Soeharto. (2020). The ability of indonesian language education students in designing lesson plan through teaching practice in school. Universal Journal of Educational Research, 8(11), 5489-5497. https://doi.org/10.13189/ujer.2020.081152

Prasetiyo, W. H., Ishak, N. A., Basit, A., Dewantara, J. A., Hidayat, O. T., Casmana, A. R., \& Muhibbin, A. (2020). Caring for the environment in an inclusive school: The Adiwiyata Green School program in Indonesia. Issues in Educational Research, 30(3), 2020.

Riduwan. (2006a). Belajar Mudah Penelitian Untuk Guru Karyawan dan Peneliti Muda. Alfabeta.

Riduwan. (2006b). Metode dan Teknik Menyusun Tesis. Alfabeta.

Robbins, P. S. (2002). Prinsip-Prinsip Perilaku Organisasi. Edisi Kelima. Diterjemahkan oleh: Halida, S.E dan Dewi Sartika, S.S. Jakarta.

Santoso, Singgih. (2000). SPSS : Statistik Parametrik. Elek Media Komputindo.

Santoso, Slamet. (2010). Teori Psikologi Sosial. PT. Rafika Aditama.

Singarimbun, M., \& Efendi. (1995). Metode Penelitian Survey. PT. Pustaka LP3ES. Simamora, Bilson.

Slameto. (2010). Belajar dan Faktor-Faktor yang Mempengaruhinya. Rineka Cipta.

Supardi. (2005). Metode Penelitian Ekonomi dan Bisnis. UII Press. Suryabrata.

Wijaya, A. K., Giyono, U., \& Adha, M. M. (2020). Kontribusi Pembelajaran 
Jurnal Pendidikan Pancasila dan Kewarganegaraan

Volume II Nomor 1 (April) 2021

Pendidikan Kewarganegaraan Menggunakan Model Role Playinguntuk Pengembangan Keterampilan Intelektual Siswa. Jurnal Pendidikan PKN (Pancasila Dan Kewarganegaraan), 1(2), 130. https://doi.org/10.26418/jppkn.v1i2.41253 